\title{
The Mexican Tourism Business: Lessons From Domestic Demand For Business Managers
}

\author{
Liliana Ruiz Fuentes, Universidad del Valle de México, Mexico
}

Delfino Vargas Chanes, PUED-Universidad Nacional Autónoma de México, Mexico

\begin{abstract}
The purpose of this research is to identify priority actions to be taken in Mexico in order to encourage tourism entrepreneurs to take advantage of and to meet domestic tourist demand. In order to do this, the role that domestic tourism has in consumption and demand both nationally and internationally is analysed; opinion leaders from the sector are interviewed and the concept mapping methodology is used in combination with multidimensional scaling to solve the difficulties of prioritizing activities, gaining consensus, and to show graphically how the various stakeholders relate. The main results show three principal groups of activities: one which can be directly addressed by entrepreneurs, and two others, which although they relate to public policy and measurement, can also be driven by the business community.
\end{abstract}

Keywords: Concept Mapping; Domestic Tourism; Business Managers; Multidimensional Scaling

\section{INTRODUCTION}

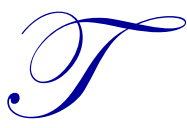

he Mexican tourism industry has had an international market focus since the boom of the 70s; in this way, Mexico maintained a position among the top ten tourist destinations in the world for decades. This triggered the development of a great deal of tourism supply which is today embodied in infrastructure and superstructure useful for the effective functioning of the industry. Furthermore, it has encouraged foreign direct investment, which has in turn generated additional benefits such as employment.

Notwithstanding the above, from the late twentieth and early twenty-first centuries, competition in the international arena has intensified; high growth in tourist activities over the last decades in emerging economies such as the BRICs, along with other nations, has displaced Mexico from the positions it once occupied in terms of both tourist arrivals and income generated. In addition to the challenge of increased international competition are other factors that have modified international travel habits and the growth trends of international tourism with a tendency towards shorter trips within the same region (OMT, 2016; OMT, 1999; OECD, 2016). Within the Americas region, the issue of the organized crime activities has generated a perception of insecurity for the two main sources of tourists to Mexico the United States and Canada. -

Against this background, domestic tourism presents an opportunity for entrepreneurs in the sector. It is known that in Mexico domestic tourism consumption represents $89.8 \%$ of the total tourism consumption in the territory and continues to grow (INEGI, 2015). It is also known that $45.4 \%$ of households undertook a trip in 2013 (SECTUR, 2014). Similarly, the tourism entrepreneurs themselves acknowledge that during crisis periods, such as the 2008 financial crisis, domestic tourism has been fallen back on as an opportunity for increasing hotel occupancy levels, including in destinations traditionally focused on international tourism such as Cancun.

So arises the question as to how Mexico can create favourable conditions that allow tourism entrepreneurs to take advantage of domestic demand. To respond to the outlined competitive environment, leveraging domestic demand, this research has its foundations in the demand theory Vellas and Bécherel (1999) applied to tourism, in which it is 
argued that to compete in international markets it is advisable to first develop the domestic market, taking advantage of the natural advantages and technologies in a country.

The work carried out draws on three sources of information: a) the analysis of information of the Tourist Consumption Index (TCI) (Ruiz \& Vargas, 2010); b) interviews with opinion leaders (Ruiz Fuentes, 2012); and, c) the optimal prioritization of actions, utilizing the concept mapping technique (Trochim, 2008).

The main purpose of this research is to identify priority actions to be taken in Mexico so that entrepreneurs take advantage of and meet domestic demand for tourism. In this respect, it is essential that entrepreneurs in the tourism sector place greater emphasis on the importance of domestic tourism, and secondly that they find new ways to prioritize activities to be undertaken in order to meet domestic demand.

This investigation is organized as follows: the first section presents a review of the tourism demand and domestic tourism literature, as well as of their study and measurement; subsequently, the specifications of concept mapping as an analysis technique are presented together with the main data characteristics; the penultimate section outlines the results, before a final section sets out the conclusions and future suggested lines of research.

\section{Tourist Demand}

Many authors agree (Goeldner, Ritchie \& McIntosch, 2000; Figuerola, 2005; Bull, 1995; Gunn, 1989) that the study of the behavior of tourist demand has piqued a large interest both in academia as well as the public and private sectors, since it is essential in any tourist business situation because of its dependence on the flow of tourists and other social, political and environmental impacts generated by it; in this sense, for the case of Mexico, the literature is abundant with studies on international tourism (SECTUR, 2014).

As background information on the demand theory approach used in this investigation, Leontief (1956) questioned the empirical validity of the supply approach, in particular from the resource endowment theory. His research suggests that in the United States, at the time the nation with the most abundant capital, neither produced nor exported capital goods as would have been expected but rather exported labour-intensive goods. This analysis, commonly known as Leontief's Paradox, was responded to by Linder (1961) who proposed the demand characteristics theory. Based on his analysis, noted that differences in resource endowments between countries didn't always reflect international exchanges, what is more, he identified that exchanges are often made between countries with economies with similar endowments. From the above came the demand theory, which instead of referring to the resource endowments available to countries it considered interior or domestic demand. According to Linder's proposal (1961), the international specialization of a country depends to a high level on domestic demand.

\section{Domestic Tourism}

With regard to the importance of domestic tourism, Figuerola (2000, pg. 94) explains that "when foreign tourist receipts are converted into national currency, having positively influenced the balance of payments, the induced effects on the domestic production process and on employment, other repercussions aside, are identical to the effects caused by the consumption of goods and services by tourists residing in the territorial space studied" [translated from Spanish original]. Notwithstanding this explanation, it is often believed that more attention should be placed on non-resident tourist consumption under the belief that, because they provide external economic inflows, it has greater influence on the economic system. Nevertheless, it is clear that both international tourist flows as well as domestic demand contribute to economic development, based on the belief that those variables which comprise aggregate demand, stimulate the factors of production.

For instance, in the principal tourist recipient countries (France, USA, Canada, Germany, Switzerland, and the United Kingdom), international tourist demand complements high domestic demand. This in turn results in the comparative advantage of these countries being high, estimated from the quality of their infrastructure and superstructure, especially in terms of their expertise and knowledge with regard to tourism, their level of technology, and from their favourable environments for tourism (Vellas \& Bècherel, 1999). 
Thus, this investigation is based on upon the postulations of the demand theory. This theory proposes that in a country where the domestic tourist market is served, it is developed the necessary expertise and infrastructure, which consequently facilitate the reception of international tourism and the maintenance of leadership. Furthermore, the tourist consumption index (Ruiz \& Vargas, 2010) provides empirical evidence demonstrating that the tourist consumption of residents is the variable which coincides to the greatest extent with the behaviour of aggregate tourist demand, across 53 nations and over a time frame of 10 years as analysed by the TCI.

\section{Sources and Methods}

Econometric methods are frequently employed for the study of tourist demand (Kamel, Ftiti, \& Chaibi, 2015), and to a lesser extent, other multivariate methods are utilised, such as factor analysis; their use is justified as they allow the analysis of various variables simultaneously and do not necessarily try to explain only a single dependent variable.

This study takes a distinct approach and consequently requires the application of other methods in order to respond to the research question concerning the manner in which Mexico can create favourable conditions allowing tourism entrepreneurs to take advantage of domestic demand. For this purpose, semi-structured interviews were conducted with stakeholders relevant to tourist activities and the method of concept mapping with multidimensional scaling was applied (Trochim, 2008).

The implementation of the semi-structured interviews lays the foundation for the application of the concept mapping technique while also representing circumstantial evidence of the role of domestic tourist consumption in tourism in Mexico. The recommendations and assessments generated during the interviews by experts from the sector suggest issues to be addressed in order to promote domestic tourism in Mexico, and from their distinct perspectives (entrepreneurs, public servants, journalists, academics), they call attention to aspects which they consider to be priorities.

Despite the valuable information obtained during the interviews, when one tries to generate a domestic tourism strategy for Mexico, it is difficult to objectively prioritise these recommended actions. In order to overcome this difficulty, the concept mapping method was utilized.

\section{The Concept Mapping Method}

In the literature review, various methods can be found for the graphical representation of concepts translated into maps; from the most qualitative approaches, such as the method utilized for better use of answers obtained during research interviews (Kinchin, Streatfield, \& Hay, 2010), to others which apply a diverse range of statistical methods for the representation of ideas or concepts in maps such as coding (Chei-Chiang, 2009), hierarchical structure of scores and variance analysis, among others (Gill \& Persson, 2008). For the purpose of this research, multidimensional scaling is used (Lattin, Carroll, \& Green, 2003).

Concept mapping is a multidimensional method used for the structured conceptualization of complex problems; the method comprises a graphical representation of the thinking of a group which presents its ideas on a theme (Vargas Chanes \& Merino, 2011). In this particular case, the theme concerns the manner within which Mexico can create favourable conditions allowing entrepreneurs to take advantage of domestic tourism demand.

In order to construct a concept map, the first step involves compiling a list of statements based on the responses obtained during the semi-structured interviews with stakeholders; then, the relationships between these responses are structured and then the data is analysed using multivariate statistical techniques; more specifically, the techniques of multidimensional scaling and latent class analysis. The maps are constructed based on the results and the information that is obtained is interpreted. 
Table 1. Process for the elaboration of concept maps.

\begin{tabular}{|c|c|}
\hline Stage & Manner of obtaining information \\
\hline 1. Generation of ideas by selected stakeholders. & $\begin{array}{l}\text { In this case, it was based upon the answers obtained during the } \\
\text { semi-structured interviews. }\end{array}$ \\
\hline 2. Classification of ideas by relevant themes. & $\begin{array}{l}\text { Each participating stakeholder creates groups which they } \\
\text { define according to their criteria. }\end{array}$ \\
\hline $\begin{array}{l}\text { 3. Prioritization of ideas based on the level of importance and } \\
\text { evaluate their performance. }\end{array}$ & $\begin{array}{l}\text { Using a Likert scale of } 1-5 \text {, each stakeholder prioritizes } \\
\text { according to their criteria. }\end{array}$ \\
\hline 4. Representation of ideas and the generation of maps. & Multidimensional scaling and cluster analyses are undertaken. \\
\hline 5. Interpretation of conceptual maps. & Drawn from the results of the latent class analysis. \\
\hline
\end{tabular}

In stage one, during the interviews, statements arise from the textual quotation of the interviewees; in this case there are 61 statements. Following the recommendations of Trochim (2008), modifications are made such that the sentences are written in a positive form; that is to say, if the interviewee mentions that "air travel is very expensive for national tourists and it is common that it is cheaper to travel from Mexico City to Miami than from Mexico City to some Mexican beach destinations", the statement is replaced with "Offer competitive air travel prices". The list of statements can be found in the Appendix "Elements of the conceptual map".

In stage two, together with the invitation to participate, the experts were sent a text concerning the concept mapping method which also instructed them to group the statements and assign names to each group. In total 23 opinion leaders participated in the study be it as interviewees and/or in the concept mapping session. Thirteen experts answered the worksheet, which though a small group, they share the characteristic of a having extensive experience in tourism both in Mexico but also, as is relevant, at the international level too (see Figure 1). Moreover, according to Trochim (2008, pg. 6), 13 is a sufficient number for obtaining results from a concept map.

In stage three, the stakeholders were given a worksheet and were asked to rank both the importance and performance of each statement. The ranking of the statements is based on a Likert-scale of 1 to 5 where 1 represents low importance and 5 represents high importance. The performance is rated from very poor, 1, to excellent, 5 . This is shown clearly in Figure 2.

The interpretation of results is conducted in three stages: 1) a map is presented on the stakeholders' evaluation of the importance and performance of each item; 2) then, more precisely, another map, known as a common spaces map, presents the way in which stakeholders have not only assigned a value to the importance and to the performance of each item (understanding the items as variables), but which also allows an interpretation of the way in which the variables relate to each other; 3 ) in a third stage, based on a latent class analysis, the classes or groups of variables on the common spaces map are identified, and ranked by importance. Once the three stages have been concluded, it is possible to propose an action plan based on the findings, as explained below.

\section{RESULTS}

Probably the most complicated activity, which relates the elaboration of a plan for prioritizing the activities that Mexico could undertake in order to best take advantage of domestic tourism, will always be the first step as the results will depend on the way in which the plan is conceptualized. In this sense, the main advantage of using statistical analysis to analyse the responses of the tourist experts, as Monk-Goldsmith mentions, is the fact that "it avoids potential problems relating to bias, eliminating the intervention of the researcher in the interpretation of ideas" (2009, p. 54) [translated from Spanish original].

In order to analyze the results of the application of the concept mapping technique in the first stage, based on the expert's responses, it is possible to graphically identify the importance and performance attributed to each statement (See Figure 2). To begin this analysis, in quadrant 2, we identify those statements to which the experts assign a high importance and a low performance, which imply that they are both very important and lack the necessary performance, and thus represent the principal activities to be taken care of so that entrepreneurs can better take advantage of domestic tourist demand. Even within this quadrant differing levels of priority exist; for example, items 22 and 5 have the same 
level of importance, but differing performances, as tourism culture performance (item 5) is rated above the domestic tourism spending potential (item 22).

Continuing with the analysis of the importance-performance map quadrants, quadrant 1 contains those items to which stakeholders assign both high importance and high performance. Quadrant 4 displays those variables which have a high performance, but a low importance, and the final quadrant shows those variables which stakeholders consider to have both low importance and low performance.

Looking at the map in Figure 2, it is easily observed that a large number of the items are located very close to the graph's origin, or rather, very close to the boundaries between one quadrant and another. As such, in order to develop a plan that allows entrepreneurs to better take advantage of domestic tourist demand, it is difficult to assign the priority level of an item that rests on the border of quadrant 2 (focus here) and quadrant 3 (ignore).

In order to resolve this ambiguity, in the second stage of the analysis, multidimensional scaling, stemming from the groupings of items made by the participants, is used. This results in the representation of the items in a twodimensional graph, where they are not only placed by the importance-performance levels assigned to them, but also by the way in which the experts have indicated they relate to each other. In other words, the coordinates do not represent information in respect to the variable in question but rather they offer information concerning the variable with respect to the group of variables. Applying multidimensional scaling resolves the interpretational challenges presented by the importance-performance map and places each variable more precisely at a single point on the map of common spaces.

The map of common spaces is the graphical expression of the place occupied by the items and the relationship between them. The graph facilitates interpretation with respect to the level of priorities in the elaboration of an action plan to enhance domestic tourism as well as the way in which the experts visualize it.

An element to take into account in the map of common spaces is the adjustment measure, presented as the stress factor. As this figure approaches zero, the implication is that the solution found in the graphical representation is increasingly accurate. The stress-level shown by this piece of research is .28 , indicating a modest adjustment, but as explained by Monk-Goldsmith (2009) a small sample size (13 participants) within the acceptable range (10-20 participants) tends to produce this effect. On the contrary, a stress value that is too close to zero $(>0.2)$ can indicate an over adjustment which can have negative impacts on interpretation. In addition to the stress factor, it is relevant that the resultant map has meaning and utility for the purposes pursued by this research.

Continuing with the activities of the second stage of the analysis, the expert participants' responses are populated in a binary similarity matrix, which collects the way in which the participants grouped the items (variables) and allows a total to be calculated for each one. When applying multidimensional scaling, with a basis in this similarity matrix, coordinates which place each item on the map of common spaces are obtained. This map shows the relative similarity and the distance of an item with and from the others, as well as the priority of the items, combining interval scale criteria with strata criteria (see Figure 3). 
Figure 1. Map of importance vs. performance

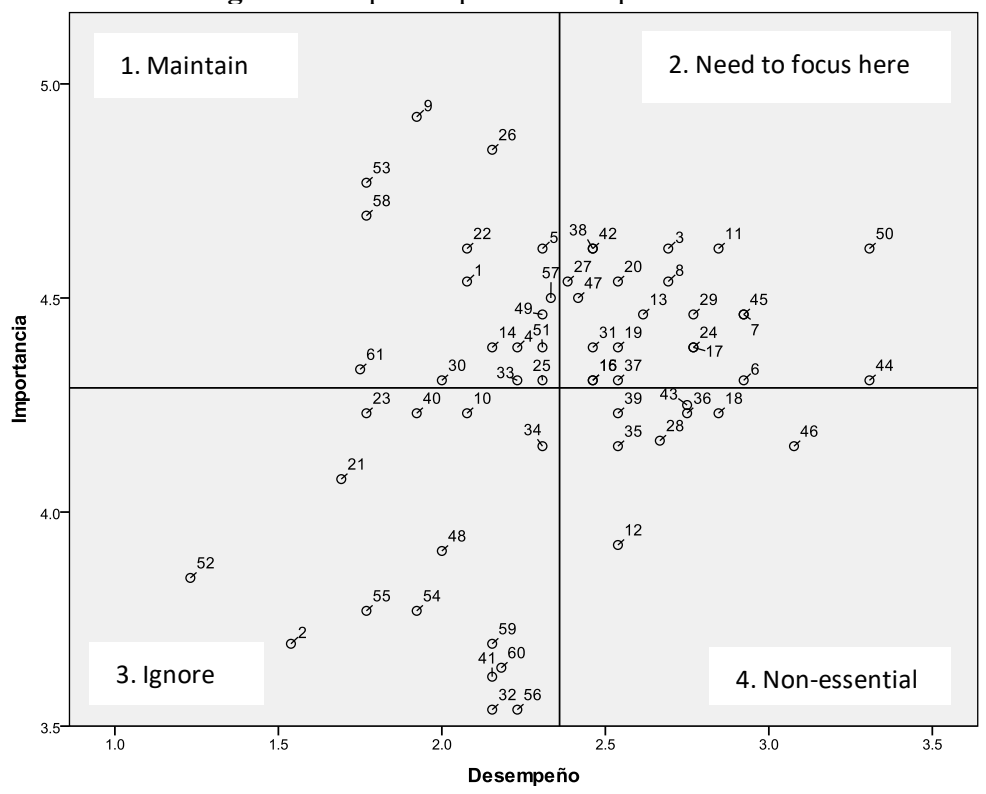

Figure 2. Map of common spaces with the level of relevance of the statements

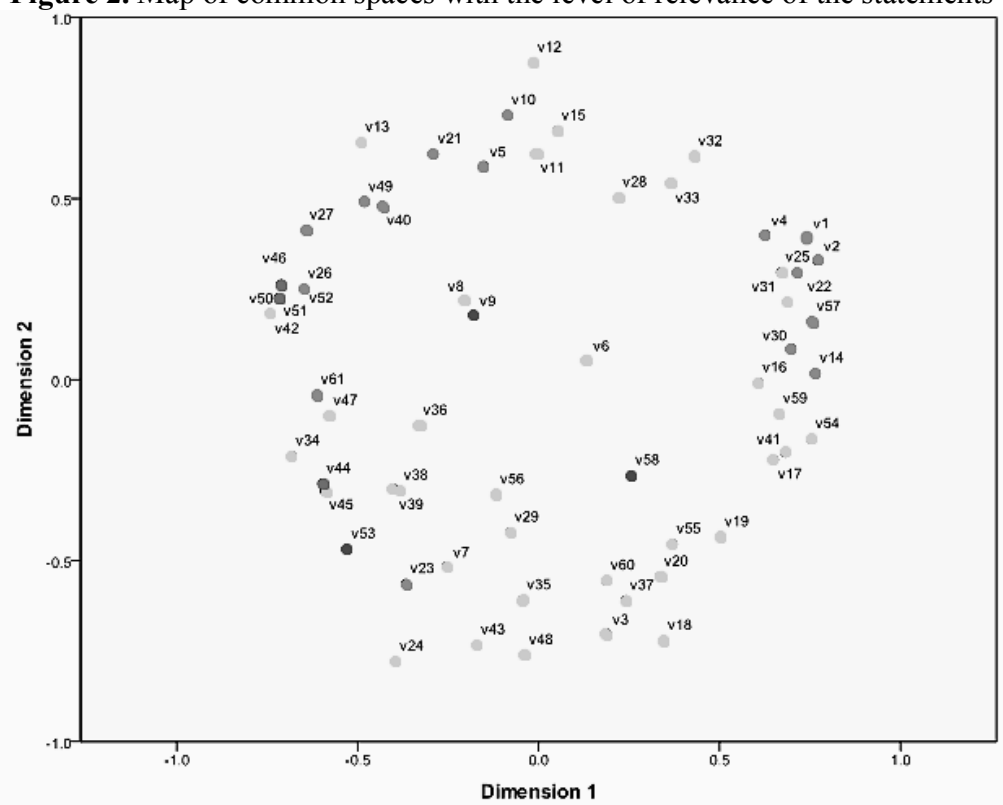

Note: the gray scale represents the priority of the items, combining the interval scale criteria with the strata criteria. The grey tones indicate the following: 1) very significant items labelled as "priority" (shown in black); 2) highly significant items labelled as "important" (in dark gray); 3) moderately important items labelled "less important" (in dark gray with an outline); and 4) insignificant items labeled as "minimally important" (in light gray). A variable is considered more significant insofar as it is more relevant in the strategy to enhance the participation of entrepreneurs in domestic tourism in Mexico.

From Table 2, it can be determined that the optimal number of classes or groups is three. According to the criteria specified in the table (Vargas, 2018), this selection helps to better conceptualize the groups formed and to determine the number of classes a latent class analysis is applied (Hagenaars \& McCutheon, 2002) using each items coordinates, obtained through multidimensional scaling. 
Table 2. Class selection criteria

\begin{tabular}{c|c|c|c|c|c}
\hline Class & Index BIC Adj. & LMR Pr & Entropy & $\begin{array}{c}\text { \% of group } \\
\text { belonging }\end{array}$ & $\begin{array}{c}\text { Probability of } \\
\text { membership }\end{array}$ \\
\hline 1 & 167.675 & n.a. & n.a. & n.a. & n.a. \\
\hline 2 & 156.039 & .0207 & 0.827 & 35,26 & $.95, .96$ \\
\hline 3 & 149.427 & .4999 & 0.849 & $24,19,18$ & $.93, .97, .92$ \\
\hline 4 & 176.610 & .2632 & 0.886 & $14,9,21,17$ & $.90, .86, .96, .96$ \\
\hline
\end{tabular}

Note: The procedure to determine the number of latent classes requires five criteria (Jones, Nagin, \& Roeder, 2001): 1) The Bayes information criteria indicates that the smaller the value is the better the model's adjustment (Schwartz, 1978) (Sclove, 1987); 2) the entropy score should be higher (values closer to the unit indicate a better fit); 3) The Lo-Mendel-Rubin statistic must indicate a significant probability value (a value $\mathrm{p}<$ 0.05 , Lo, Mendell \& Rubin, 2001); 4) all trajectory groups must contain a reasonable proportion of the sample where at least $5 \%$ of the observations are classified with a group, and 5) the probability of belonging to each group be at least .85 .

The map formed is shown in figure 4, and situates the following three concepts: 1) Planning; 2) Identification of demand characteristics; and 3) Supply. The priority of each of the groups is obtained from the level of importance of the items within in.

Figure 3. Map of groups with interval scale

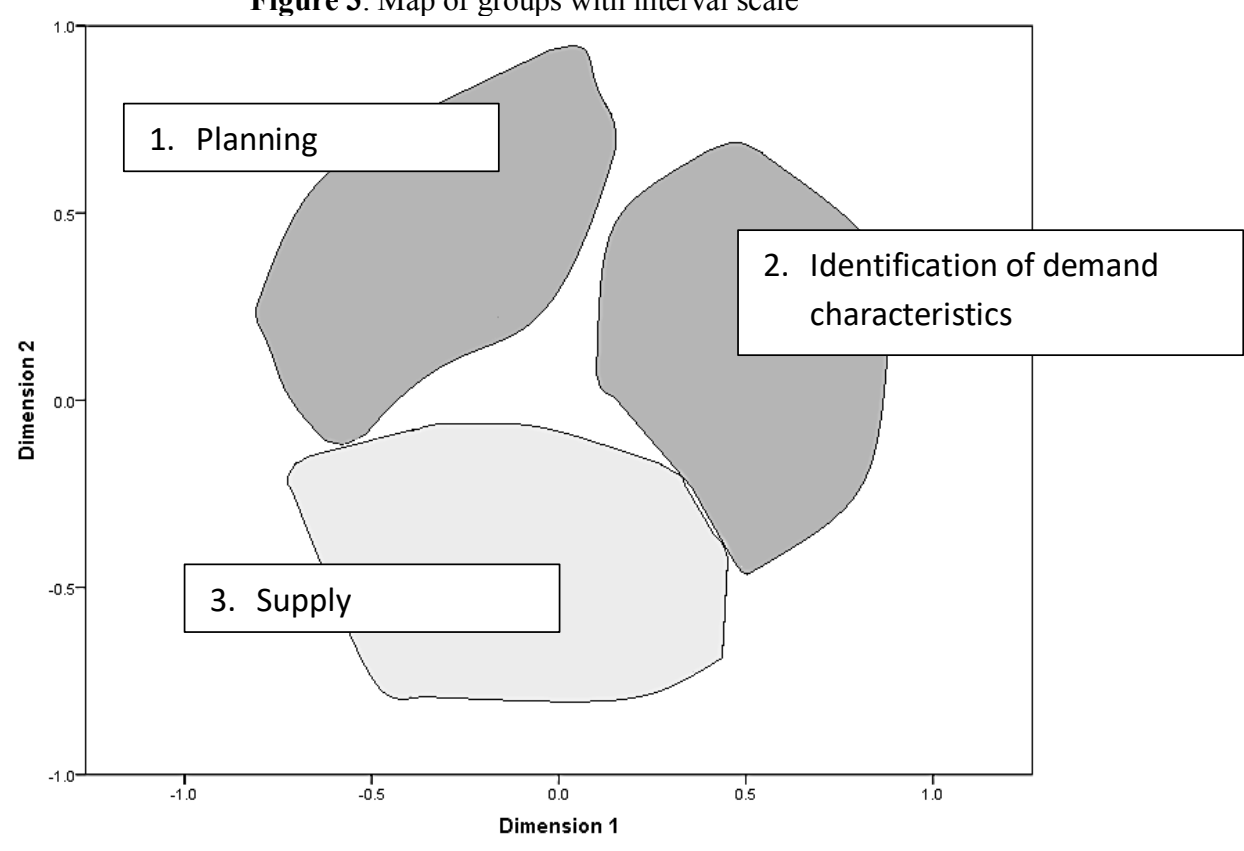

This map shows the manner within which the stakeholders group the actions that could contribute to boosting the extent to which entrepreneurs are able to take advantage of domestic tourism in Mexico; three groups are identified as well as the relevance of each (based on the level of importance of the items contained within each). Group 1, Planning, while only slightly higher than Group 2, Identification of demand characteristics, has the highest level of relevance, while Group 3, Supply, has the lowest level of relevance.

The latent class analysis findings show that one priority activity and nine important ones fall in Group 1, Planning. These activities are as follows: 1) the need to create a national domestic tourism plan that is congruent with the state's budgets as well as that of the Tourism Promotion Council (this is the only priority statement in this group, the rest are important); 2) ensure safety on the roads; 3 ) meet the needs of tourists with limited resources, who have been identified as generating a high occupation in hotels which they can afford; 4) have redistributive policies so that income captured by tourism is reinvested in support of the sector's competitiveness; 5) generate policy to guide capital investment in the most appropriate way; 6) tourism culture in Mexico is an essential element that favors internal tourism; 7) conduct activities to ensure that the receiving communities in tourist destinations recognize the importance of internal tourism; 
8) implement fiscal strategies; for example, that the deductibility of taxes on consumption in restaurants is greater; 9) provide adequate signage on roads and in destinations.

In group 2, Identify demand characteristics, there are no priority activities, but there are seven important activities, which are: 1) measure the potential for domestic tourism spending in Mexico; 2) have adequate mechanisms to measure the number of internal trips that Mexicans make in Mexico; 3) have in-depth regional studies which describe the elements which influence the decision taking moment for internal tourism; 4) conduct exit surveys in order to understand the extent to which needs were met in various destinations in terms of value for money, attractions, diversity of activities, etc.; 5) register the place of origin of visitors to weekend tourist attractions; 6) have supply in Mexico to meet the demands of those tourists who travel to the USA; 7) have a select group of households upon which periodic surveys are conducted concerning their trips within Mexico.

Finally, Group 3, Supply, despite being the group of least importance, contains two priority actions: 1) develop strategies to incentivize internal tourism, taking the population's income into account (consumption is positively correlated with the equal distribution of income);2) offer competitive air travel prices. The supply group also contains an important activity, which is: have a price discrimination strategy and policy for internal tourism.

The activities identified as less relevant are: 1) to have quality lodging in a range of destinations distinct from those of sun and beach; 2) facilitate mobility within destinations (for example, the mobility of tourists within CDMX when visiting); 3) Provide a road network in good condition. The low priority assigned to these three activities seems to be attributable to the fact that experts consider that these activities are already being adequately addressed; with respect to the road network being in good condition, it was only those interviewees who travel to remote places within the country who positioned this need as indispensable.

\section{CONCLUSIONS}

The items for boosting domestic tourism consumption, as identified by stakeholders, can be grouped into three classes: one of tourist planning activities, a second concerning the characteristics of demand, and a third related to supply. From these three groups, the group containing activities relating to planning is considered the priority. The second cluster concerns activities with a focus on knowing and measuring the characteristics of demand, such as the need to measure the potential of domestic tourism in Mexico and identifying internal travel decision making elements. The third group, concerning supply, recognizes the need to serve lower categories of hotel supply which give high occupancy rates. Of these three activity groups, the supply segment can be directly addressed by the entrepreneurs, and the other two, although they are more linked to public policy and the measurement of domestic tourism, can also be driven from the business sector itself.

The map of common spaces represents the way in which the experts associate the items (or the variables represented by the statements) that could boost domestic tourism in Mexico. In this sense, it should be noted that despite the research falling within a specific sector, as tourism is, the perspectives of the participants are very diverse owing to the focuses from which each approaches the theme.

It is interesting to note that from the diverse perspectives of the interviewed stakeholders, there is a high frequency of convergence in their proposals and opinions in terms of the opportunity that the enhancement of domestic tourism in Mexico could represent. During the interviews, it was identified that while the entrepreneurs tend to emphasize the need for public policy instruments that enhance the activity as well as focus on very particular aspects of tourism and go directly to action, academics tend to emphasize the need to measure and evaluate as well as to consider tourism within a much broader context. The diversity makes it difficult to analyze the responses together, a challenge which is solved through the application of multidimensional scaling and locating each item on the common spaces map.

The conceptual mapping method is useful both for graphically visualizing the manner within which the experts relate the statements and for discerning which activities should be considered a priority in terms of enhancing the scope for entrepreneurs to take advantage of domestic tourist demand in Mexico. The method is useful in achieving the research objective of providing entrepreneurs who are interested in taking advantage of the domestic tourist demand in Mexico with information and answers the research question. 
Based on the conclusions, it is relevant to conduct research at the regional level in Mexico to support the development of action plans for entrepreneurs to better take advantage of domestic tourist demand. A second identified opportunity would be to deepen the analysis of each identified group in such a way that, for example, the actions in the supply group can be addressed by entrepreneurs in the tourism sector.

\section{AUTHOR BIOGRAPHIES}

Dr. Liliana Ruiz Fuentes is a research professor at UVM as part of the Laureate International Universities and has been in the education business for the last 20 years. She holds a doctorate in Economic Development and Tourism by Antonio de Nebrija University in Madrid, Spain; obtained her MBA with focus in finance and a Bachelor degree in Management and Tourism at Universidad Anáhuac. Her research interest is Corporate Entrepreneurship. Email: liliana.ruiz@uvmnet.edu

Dr. Delfino Vargas Chanes is a research professor of the University Program of Development Studies, UNAM. He obtained a doctorate in Sociology from Iowa State University (Ph.D., 2000), a Master's Degree in Sociology (1996) and Statistics (1994), both from the State University of Iowa, with a degree in Mathematics (1982) by the UNAM. He has published more than 40 articles in various national and international refereed academic journals. His research interests are inequality and poverty, and the development of advanced quantitative methodologies for social research. He is a national researcher, level II. Email: dvchanes@gmail.com

\section{REFERENCES}

Bull, A. (1995). The economics of travel \& tourism (2nd ed.). Melbourne, Australia : Addisson Wesley .

Chei-Chiang, C. (2009). Effects of concept mapping strategy on learning performance in business \& economics statistics. (T. \&. Group, Ed.) Teaching in Higer Education, 14(1), 55-69.

Figuerola, M. (2000). Introducción al estudio económico del turismo . Madrid, España: Civitas .

Figuerola, M. (2005). Apuntes de metodología de la investigación en turismo . Doctorado en Turismo . Madrid, España: Universidad Antonio de Nebrija.

Gill, P., \& Persson, M. (2008). On Using Concept Maps to Study School Childrens Understanding of Leisure Time. (T. \&. Group, Ed.) Leisure Studies, 27(2), 213-220.

Goeldner, C., Ritchie, B., \& McIntosh, R. (2000). Tourism: principles, practices and philosophies (8th ed.). USA: John Wiley \& Sons.

Gunn, C. (1989). Tourism planning. New York, USA: Adisson W.

Hagenaars, J., \& McCutheon, A. (2002). Applied latent class analysis. Cambridge: Cambridge University Press.

INEGI (2015). www.inegi.org.mx. Recuperado el 05 de Julio de 2016, de www.inegi.org.mx: http://www.inegi.org.mx/saladeprensa/aproposito/2015/turismo0.pdf

Jones, B., Nagin, D., \& Roeder, K. (2001). A SAS procedure based on mixture models for estimating developmental trajectories. Sociological Methods and Research, 29(3), 374-493.

Kamel, J., Ftiti, Z., \& Chaibi, H. (2015). The Tunisian tourism business: What we learn about the european demand? The Journal of Applied Business Research, 31(6), 2079-2090.

Kinchin, I., Streatfield, D., \& Hay, D. (2010). Using concept mapping to enhance the research interview. (U. O. Alberta, Ed.) International Journal of Qualitative Methods, 9(1), 52-68.

Lattin, J., Carroll, D., \& Green, P. (2003). Analyzing Multivariate Data. Toronto, Canadá: Thomson.

Leontief, W. (1956). Factor proportions and the structure of american trade further theoretical and empirical analysis. R.E.S.

Linder, S. (1961). An essay on trade and transformation. New York : John Wiley \& Sons.

Monk-Goldsmith, K. (2009). Factores Percibidos que Impiden a las Personas con Discapacidad Entrar al Sector Laboral en México. Instituto Autónomo de México, Mestría en Administración . México DF. : Sin Publicar .

OECD (2016). Tourism Trends and Policies 2016. Paris: OECD Publishing.

OMT (1999). Turismo Panorama 2020, Nuevas previsiones de la OMT. Madrid, España: Organización Mundial de Turismo. OMT (2016). UNWTO Annual Report 2015. Madrid: UNWTO.

Ruiz Fuentes, L. (2012). Potenciación de la demanda turística, con base en el análisis del consumo turístico agregado a nivel internacional de 1998 a 2009: El caso de México . Universidad Antonio de Nebrija, Facultad de Negocios . Madrid: Universidad Antonio de Nebrija .

Ruiz, L., \& Vargas, D. (2010). Índice de demanda turística agregada. Anáhuac Journal, 10(2), 27-31.

Schwartz, G. (1978). Estimating the dimension of a model. The Annals of Statistics(6), 461-464.

Sclove, L. (1987). Application of model selection criteria to some problems in multivariate analysis. Psychometrika, 52, $333-343$.

SECTUR (2014). http://www.datatur.sectur.gob.mx. (S. d. Turistica, Ed.) Recuperado el 05 de Julio de 2016, de http://www.datatur.sectur.gob.mx: http://www.datatur.sectur.gob.mx/SitePages/Iniciobanner2.aspx 
Trochim, W. (2008). An introduction to concept mapping for planning and evaluation. Cornell University.

Vargas Chanes, D., \& Merino, M. (2011). Estudio de los Espacios Públicos desde la Perspectiva de los Actores Sociales: Aplicación del Concept Mapping. Secretaría de Desarrollo Social. Programa de Rescate de Espacios Públicos., Documento interno. México.: Documento Interno. Secretaría de Desarrollo Social. Programa de Rescate de Espacios Públicos.

Vargas, D. (2018). Curso modelos estructurales para datos de sección. Ciudad de México.: Universidad Nacional Autónoma de México (UNAM-IIMAS).

Vellas, F., \& Bècherel, L. (1999). The international marketing of travel and tourism: a strategic approach. London: Macmillan. 


\section{APPENDIX}

\section{ITEMS FOR CONCEPTUAL MAP}

1. Have adequate mechanisms to measure the number of internal trips that Mexicans make in Mexico;

2. Have a select group of households upon which periodic surveys are conducted concerning their trips within Mexico;

3. Make it that short weekend trips be more common among domestic tourists;

4. Register the place of origin of visitors to weekend tourist attractions;

5. Tourism culture in Mexico is an essential element that favors internal tourism;

6. Stimulating the sense of belonging towards Mexico within Mexicans could enhance the number of domestic tourist trips;

7. Generate mechanisms that encourage states and municipalities to invest in promotion and publicity with the aim of stimulating domestic tourism;

8. Have a national plan to guide actions to promote domestic tourism;

9. Have a national domestic tourism plan that is congruent with the state's budgets as well as that of the Tourism Promotion Council;

10. Conduct activities to ensure that the receiving communities in tourist destinations recognize the importance of internal tourism;

11. Carry out activities so that service providers know the relationship between service, quality, price, and competitiveness of services so that domestic tourists repeat their trips;

12. Train local guides to receive and attend to national tourists;

13. Undertake actions which favor the management of tourism in destinations, with a focus on identifying the role of the municipality and other actors;

14. Conduct exit surveys in order to understand the extent to which needs were met in various destinations in terms of value for money, attractions, diversity of activities;

15. Ensure that each of the local tourism secretariats is clear of the image domestic tourists have of that destination;

16. Have information concerning the domestic tourism market segments which facilitates service provider decision making;

17. Know the factors considered by tourists at the moment the decision to make a domestic trip is made;

18. Supply real information in the media for the promotion and advertisement of domestic tourism;

19. Identify which advertising channels each domestic tourist niche is exposed to;

20. Have an appropriate strategy to maximize the use of information technologies for the promotion of domestic tourism;

21. Have redistributive policies so that income captured by tourism is reinvested in support of the sector's competitiveness;

22. Measure the potential for domestic tourism spending in Mexico;

23. Have a price discrimination strategy and policy for domestic tourism;

24. Provide domestic tourism credit and appropriate distribution channels;

25. Quantify the impact of mechanisms such as long weekends in terms of increases in domestic tourism;

26. Ensure safety on the roads;

27. Provide adequate signage on roads and in destinations;

28. Detonate investments that generate an increase in the average length of stay of domestic tourists;

29. Coordinate and promote the recently developed tourism supply for use by domestic tourists (for example, the conservation program of the Sierra Gorda in Querétaro, ecotourism in Mazunte and Calpulalpan de Méndez in Oaxaca, Sierra Chincua in Michoacán with the monarch butterflies, Frontera Corozal en Chiapas, Cuatro Ciénegas in Coahuila, among others);

30. Have in-depth regional studies which describe the elements which influence the decision taking moment for internal tourism;

31. Have studies that quantity domestic tourism's contribution to dynamiting the economy;

32. Have studies which describe the benefits of Mexicans knowing their country better;

33. Have special official sources that offer market information and facilitate the decision making of potential investors; 
34. Coordinate service providers in the most efficient way in order to favor domestic tourism (for example through recently made routes);

35. Have well coordinated and specialized marketing channels through operators;

36. Achieve a balance in tourist destinations between quality and friendliness offered to domestic tourists;

37. Undertake actions which focus on promoting niche domestic tourism;

38. Develop an appropriate supply for domestic tourist needs;

39. Adapt existing supply to the needs of domestic tourism;

40. Generate policy to guide capital investment in the most appropriate way;

41. Identify what Mexican tourists in the USA seek;

42. Offer connectivity to domestic tourists travelling through Mexico;

43. Develop communication infrastructure (information) for tourists in Mexico;

44. To have quality lodging in a range of destinations distinct from those of sun and beach;

45. Offer quality accommodation in the 3 and 4 star categories;

46. Facilitate mobility within destinations (for example, the mobility of tourists within CDMX when visiting);

47. Combine products that offer comprehensive solutions (since one tourist buys crafts, likes gastronomy, makes excursions with the same destination, etc.;

48. Ensure that tourists have appropriate expectations as it encourages increased consumption;

49. Implement fiscal strategies: for example, that the deductibility of taxes on consumption in restaurants is greater;

50. Provide a road network in good condition;

51. Offer a wide road network;

52. Offer a rail network for the transportation of tourists;

53. Offer competitive air travel prices;

54. Understand the 13 million Mexicans who spend on tourist activities in the USA. How many of them would be willing to spend more on tourism in Mexico?;

55. Have strategies to make Mexico attractive to those Mexican tourists who travel to the USA;

56. Have supply in Mexico to meet the demands of those tourists who travel to the USA;

57. To know in detail the number of domestic trips made by Mexicans;

58. Develop strategies to incentivize internal tourism, taking the population's income into account (consumption is positively correlated with the equal distribution of income);

59. Understand if Mexicans with the spending capacity to do so opt to travel abroad;

60. To capture, within domestic tourism, a portion of the millions of Mexican tourists who visit the United States;

61. Meet the needs of tourists with limited resources, who have been identified as generating a high occupation in hotels which they can afford. 